\title{
The Effect of Magnesium Addition on the Microstructure \& Compressive Deformation Behavior of Al-Ca Alloy.
}

\author{
Prabhash Jain $^{\mathrm{a}}$, , D.P. Mondal ${ }^{\mathrm{b}}$,Rajshree Dhok ${ }^{\mathrm{a}}$, Anshul Badkul ${ }^{\mathrm{a}}$ \\ a. University Institute of Technology, Barkatulla Unversity, Bhopal India - 462026. \\ b. Advanced Materials and Processes Research Institute (CSIR), Bhopal, India-462026
}

\begin{abstract}
The Al-Ca-Mg alloys containing varying amount of $\mathrm{Mg}$ are used to study the effect of Mg addition on their microstructure and deformation behavior at varying strain rate $(0.01 / \mathrm{s}, 0.1 / \mathrm{s}, 1 / \mathrm{s})$. The material is prepared using stir casting technique. The yield stress, flow stress and elastic limit are measured from the true stress-strain graph. The strain rate sensitivity and strain-hardening exponent were also determined for each material at different strain rates. The elastic limit decreases with increases in strain rate. The strain rate sensitivity $m$ is found to be negative at a flow strain and invariant to the strain rate. Its microstructure reveals that the microstructural characteristics changes with $\mathrm{Mg}$ addition. The variation of microstructural features primarily leading to the variation of deformation behavior.
\end{abstract}

Key words: Compressive deformation; Strain-hardening exponent; strain rate sensitivity; Plastic strength coefficient; Strain rate; $M g$-content

\section{Introduction:}

Aluminum is a light and soft metal and due to its multifunctional properties, its alloys have gained considerable attention. Aluminum alloys have higher specific strength and stiffness, reasonably high ductility, good corrosion resistance and excellent thermal conductivity[1-3]. Aluminum alloys have wide applications in shipbuilding, aerospace industry and automotive industries and heat exchanger [3-4]. But Aluminum alloys have the limitation that these could not be used at higher temperature $\left(>200^{\circ} \mathrm{C}\right)$. In order to extend the use of these alloys at higher temperature, attempts have been made to make aluminum matrix composite, grain stabilisized aluminum alloys. It is reported that the eutectic of $\mathrm{Al}-\mathrm{Ca}$ system is relatively at higher temperature [5] and thus it is thought that $\mathrm{Al}-\mathrm{Ca}$ alloy maintain their strength at elevated temperature. Furthermore, it is known that $\mathrm{Al}-$ $\mathrm{Mg}$ alloy exhibits reasonably higher strength [6]. Magnesium has the best strength to weight ratio of common structural metals, and it has exceptional die-casting characteristics [7]. Shoichi Hirosawa et al [9] also examined that a small addition of $\mathrm{Mg}$ in $\mathrm{Al}-\mathrm{Li}-\mathrm{Cu}-\mathrm{Ag}-\mathrm{Zr}$ alloys markedly accelerates the formation of $\mathrm{GP}(1)$ zones , not the $\delta^{\prime}\left(\mathrm{Al}_{3} \mathrm{Li}\right)$ phase, resulting in an enhanced age- hardening, a decreased activation energy for the GP(1) zone nucleation and decrease in free-vacancies available for $\mathrm{Cu}$ and $\mathrm{Li}$ diffusion due to the preferential vacancy trapping by $\mathrm{Mg}$ atoms. It was also examined by the investigator that the $\tau$ precipitates are formed when aged at $250{ }^{\circ} \mathrm{C}$ for $5 \mathrm{~h}$ in AlMnZn- $(\mathrm{Mg})$ alloy with $5.49 \% \mathrm{Mg}$ addition [10]. It is further reported by these investigators that. the hardness and galvanic efficiency of the alloy is improved due to $\mathrm{Mg}$ addition [10].

J. Gubicza et al. [11] has also reported that the addition of Mg in Aluminum increases the flow stress even at elevated temperature. This is attributed to the fact that the microstructure of the alloy get stable due to $\mathrm{Mg}$ addition and this is facilitated with progressive deformation. This finally results in the saturation of the flow stress at higher strains in $\mathrm{Al}-\mathrm{Mg}$ alloys. It was also reported that the fracture toughness increases with the $\mathrm{Mg}$ addition in Al-Mg alloy, while the hardness increases slightly with 3wt.\% Mg addition and then decreases when the $\mathrm{Mg}$ content increases further [12] indicating optimum $\mathrm{Mg}$ concentration is $3 \mathrm{wt} . \%$.

The present authors [13] also examined that the strength of $7010 \mathrm{Al}$-alloy (Al-Mg alloy) increases with the addition of $1 \mathrm{wt} \% \mathrm{Ca}$. The high temperature strength also increased due to $\mathrm{Ca}$ addition. However, the influence of $\mathrm{Mg}$ addition on the strength of a Al-Ca alloy, has not been examined in detailed. No attempts have been made and reported on the Effect of Magnesium Addition on the Microstructure and Deformation Behavior of Al-Ca-Mg Alloy using stirrer casting method. In this present paper, attempts have been made and characterize in terms of microstructure and compressive deformation behavior at varying strain rates at room temperature.

\section{Experimental:}

Material synthesis \& microstructure

Al-Ca-Mg alloy is prepared through the stir-casting technique. This technique involved melting of Al$2 \mathrm{wt} \% \mathrm{Ca}$ alloy in an electrical resistance furnace. Commercially pure aluminum ingot was firstly melt and cleaned. Laboratory grade Ca granules (supplied by Alfaser) were then added into the melt through mechanical 
stirring. In case of mechanical stirring, after maintaining the temperature of melt between 700 to $750{ }^{0} \mathrm{C}$, a vortex was created within the melt using a mechanical stirrer. While stirring is in progress, preheated Mg metal pieces were also added to the melt. Stirring was continued for $5-10$ minutes after addition of the $\mathrm{Ca}$ and $\mathrm{Mg}$ in the melt in order to get a better distribution. The melt temperature was then maintained at $800^{\circ} \mathrm{C}$ for half an hour, so that $\mathrm{Ca}$ and $\mathrm{Mg}$ got dissolved into the melt uniformly. Castings were prepared by pouring the melt into preheated cast iron moulds of cylindrical shapes. For microstructural observations, Al-Ca-Mg alloy sample were cut, polished and etched using the standard metallographic technique. The polished sample was etched with Keller's reagent. The microstructures of these materials were examined under a scanning electron microscope (SEM)

\section{Compressive deformation}

Compression tests were performed on a Universal Testing Machine at room temperature and at varying strain rates $(0.01 / \mathrm{s}, 0.1 / \mathrm{s}$, and $1 / \mathrm{s})$. For the compression test samples of $10 \mathrm{~mm}$ diameter and $15 \mathrm{~mm}$ length were prepared form the castings. The faces were polished and then lubricated with taplon to reduce the friction between the specimen surface and the anvil or the punch. The true stress and true strain data were recorded from the digital display and these data were used for getting true stress-true strain curves. These data were further analyzed for determination of the strain-hardening exponent, the plastic strength coefficient and the strain rate sensitivity exponent using the methodology as stated elsewhere [13]. For each material and each strain rate, tests were repeated thrice.

\section{Material and Microstructure}

\section{Results:}

The microstructure of Al-Ca-Mg alloy is shown in Fig. 1. Fig.1(a) shows that the microstructure for alloy containing $0.5 \mathrm{wt} \% \mathrm{Mg}$. it shows that the dendrites are equiaxed in nature. When $\mathrm{Mg} \%$ increased to 1 $\mathrm{wt} \% \mathrm{Mg}$, the equiaxed dendrites turned into columnar and finer dendrites, Fig.1(b). Further increase in $\mathrm{Mg} \%$, i.e., $1.5 \mathrm{wt} \% \mathrm{Mg}$, also leads to columnar and finer dendrites Fig.1(c). It is however noted that dendrites are marginally refined due to increase of $\mathrm{Mg} \%$ from $1 \mathrm{wt} \%$ to $1.5 \mathrm{wt} \%$. In the inter-dendritic region, $\mathrm{MgCa}_{2}$ and $\mathrm{AlCa}_{2}$ precipitates are observed which are confirmed through XRD (Fig. 2(a)), which are further confirmed by EDX (Fig.2(b)). The black precipitates are primarily of $\mathrm{AlCa}_{2}$. But the black spherical precipitates are found to be $\mathrm{MgCa}_{2}$. The microstructures of these alloys demonstrate that the microstructural characteristics changes with $\mathrm{Mg}$ addition.

\section{Compressive deformation}

The true stress-true strain curves of the investigated material when tested at different strain rates are shown in Fig.3. From these true stress-true strain plots, the yield stress and flow stress at different strains are determined using standard methodology. It may be noted that the curves do not show any sharp yield point. From Fig. 3 it is observed that flow stress increases with increase in $\mathrm{Mg}$ concentration. When strain rate is increased from $0.1 / \mathrm{s}$ to $1 / \mathrm{s}$ proof stress decreases, in case of $0.5 \mathrm{wt} \% \mathrm{Mg}$ containing alloy. From Fig. 3 it is further observed that when strain rate is increased from $0.1 / \mathrm{s}$ to $1 / \mathrm{s}$ proof stress decreases only marginally in case of $1 \mathrm{wt} \% \mathrm{Mg}$ containing alloy indicating proof stress almost invariant to the strain rate. On the other hand, when strain rate increases from $0.01 / \mathrm{s}$ to $0.1 / \mathrm{s}$ stress increases significantly, in case of $1.5 \mathrm{wt} \% \mathrm{Mg}$ containing alloy. In all the cases, the true stress varies to a large extent with $\mathrm{Mg}$ concentration and strain rate. But yield stress varies relatively to a less extent.

In general, it is noted that there is no sharp yield point. There is gradual change from yielding to plastic region. In the plastic region, stress increases gradually with strain indicating strain hardening. As there is no sharp yield point, the $0.2 \%$ proof stress criteria is used to calculate yield stress $\left(\sigma_{\mathrm{y}}\right)$. For better evaluation of yield stress, elastic limit stress $\left(\sigma_{\mathrm{e}}\right)$ was determined using the solving the following relations as described elsewhere [13].

The stress-strain curve of a material could be defined by the following equation:

$$
\sigma_{\mathrm{f}}=\sigma_{\mathrm{e}}+\mathrm{K} \varepsilon^{\mathrm{n}}
$$

Where $\sigma_{\mathrm{e}}$ is the elastic limit stress, $\mathrm{K}$ is the plastic strength coefficient, $\varepsilon$ is the plastic strain and $\mathrm{n}$ is the strain-hardening exponent. Eq. (1) can be written in two parts as follows:

$$
\begin{aligned}
& \sigma_{\mathrm{f}}=\sigma_{\mathrm{e}}=\mathrm{E} \varepsilon_{\mathrm{e}} \\
& \sigma_{\mathrm{f}}=\mathrm{K} \varepsilon^{\mathrm{n}}
\end{aligned}
$$


where $\mathrm{E}$ is the modulus of elasticity and $\varepsilon_{\mathrm{e}}$ is the elastic limit strain. The value of $\sigma_{\mathrm{e}}, \mathrm{K}$ and $\mathrm{n}$ are calculated using methodology described elsewhere [13].

\section{Strain-hardening exponent, Plastic Strength coefficient and Elastic limit stress}

Strain-hardening exponent is calculated from $\ln (\sigma)$ and $\ln (\varepsilon)$ plots, which were made from the recorded true stress and true strain values. Typical plots of $\ln (\sigma)$ vs. $\ln (\varepsilon)$ are shown in Fig. 4(a), and (b) for $\mathrm{Mg}$ content of $0.5 \mathrm{wt} \%$ and $1.5 \mathrm{wt} \%$ respectively. These plots show two regimes, one for elastic (lower) and other for plastic (upper) flow. It may be noted that the slope of the upper line is almost constant even though the strain rates changes. However, there is marginal variation in the slope of the lower parts of the lines. This is due to microstructural changes and manual error during experimentation error. It is also noted that the slope of lower region is close 1 . This is also analytically valid that in elastic region stress is proportional to strain. The figure also demonstrates that the intersection of the upper lines and the lower lines would also be changing with the strain rate. The stress corresponding to the intersection of these two lines is measured to be the elastic limit stress $\left(\square_{\mathrm{e}}\right)$. The stress corresponding to the point of intersection of the upper line to the stress axis is considered to the plastic strengthening coefficient, K. From these curves, 'n' strain hardening exponent, ' $\mathrm{K}$ ' plastic strength coefficient, and ' $\sigma_{\mathrm{e}}$ ' elastic limit stress are calculated using the methodology described elsewhere [13] and are reported in Table 1.

It is evident from Table 1 that the elastic limit ' $\sigma_{\mathrm{e}}$ ' of the alloy increases with increase in $\mathrm{Mg}$ concentration. Similar type of variation for strength coefficient ' $K$ ' is also noted. Both ' $\sigma_{\mathrm{e}}$ ' and ' $\mathrm{K}$ ' increases with increase in $\mathrm{Mg}$ concentration. Yield strength of the alloy ( $0.2 \%$ proof stress) also follows the similar trend of variation with $\mathrm{Mg}$ concentration. The values reported in Table 1 are the average value of three repeated tests. The standard deviation associated with these values are mostly less than $10 \%$. But in few cases, it is $\sim 15 \%$. This may be due to variation of the microstructure and chemistry in the alloy system as the alloy here considered as cast alloy. Experimental and manual errors are also associated with these values. However, the variations are mostly in accepted range of variation. Increase values of these parameters with $\mathrm{Mg}$ concentration is due to formation of finer dendritic structure and more precipitates of $\mathrm{MgCa}_{2}$ leading to more precipitation hardening and greater extent of solid solution strengthening.

Table 1: The elastic limit stress, the plastic strength coefficient and the strain hardening exponent at different strain rate

\begin{tabular}{|c|c|c|c|c|c|}
\hline $\begin{array}{c}\text { Mg content } \\
\text { (in wt\%) }\end{array}$ & Strain rate & $\begin{array}{c}\text { Elastic limit, } \\
\mathbf{\sigma}_{\mathbf{e}} \mathbf{( M P a )}\end{array}$ & $\begin{array}{c}\text { Plastic strength } \\
\text { coefficient, } \\
\mathbf{K}\end{array}$ & $\begin{array}{c}\text { strain hardening } \\
\text { coefficient, } \\
\mathbf{n}\end{array}$ & $\begin{array}{c}\text { Proof stress } \\
\mathbf{( 0 . 2 \% )} \\
\mathbf{\sigma _ { \mathbf { y } }} \mathbf{( M P a )}\end{array}$ \\
\hline \multirow{3}{*}{$0.50 \%$} & 0.01 & 45.16 & 142.88 & 0.243 & 54.243 \\
\cline { 2 - 6 } & 0.1 & 36.21 & 134.69 & 0.241 & 47.278 \\
\cline { 2 - 6 } & 1 & 35.75 & 129.95 & 0.248 & 47.482 \\
\cline { 2 - 6 } & 0.01 & 67.95 & 149.65 & 0.244 & 64.507 \\
\cline { 2 - 6 } & 0.1 & 66.72 & 149.9 & 0.238 & 66.655 \\
\hline \multirow{3}{*}{$1.50 \%$} & 1 & 64.28 & 150.98 & 0.246 & 66.122 \\
\cline { 2 - 6 } & 0.01 & 66.89 & 186.05 & 0.245 & 63.934 \\
\hline
\end{tabular}

It is interesting to note that these ' $\mathrm{K}$ ', ' $\sigma_{\mathrm{e}}$ ' and ' $\sigma_{\mathrm{y}}$ ' are function of strain rate. The trend of variation of these parameters with strain rate varies depending on the $\mathrm{Mg}$ concentration. In case of $0.5 \mathrm{wt} \% \mathrm{Mg}$, all these parameter decreases with strain rate. When $\mathrm{Mg}$ concentration increases to $1 \mathrm{wt} \%$, the value of these parameters remained almost invariant with strain rate. But, when Mg concentration increases further to $1.5 \mathrm{wt} \%$, magnitude of these parameters increases with strain rate. This signifies that $\mathrm{Mg}$ concentration influence the strain rate effect of these alloy system. At lower Mg concentration strain rate has marginally negative effect, but at higher $\mathrm{Mg}$ concentration, strain rate has positive effect. This is due to variation of microstructure with $\mathrm{Mg}$ concentration as stated earlier. On the other hand, it is interesting to note that strain hardening exponent ' $n$ ' is almost invariant with strain rate and $\mathrm{Mg}$ concentration. Strain hardening exponent is primarily dependent on the matrix and dislocation-matrix or dislocation precipitates interaction which led to dislocation multiplication and increased in dislocation density in the matrix. The matrix (the major phase) is unchanged with the $\mathrm{Mg}$ concentration. However, at higher Mg concentration, relatively larger extent of precipitates formed in the matrix which marginally increases dislocation precipitation interaction and in due course marginally greater dislocation density. As a result, marginally higher value of ' $n$ ' is expected. This is exactly observed in the case of alloy with $1.5 \mathrm{wt} \% \mathrm{Mg}$. In case of $1.5 \mathrm{wt} \% \mathrm{Mg}$, ' $\mathrm{n}$ ' also increases gradually but marginally with strain rate. This also signifies that the compressive deformation responses of $\mathrm{Al}-2 \mathrm{Ca}$ alloys are strong function of $\mathrm{Mg}$ concentration and strain rate, wherein the strain rate effect varies with $\mathrm{Mg}$ concentration. 


\section{Effect of strain rate:}

For better understanding and further analysis these parameters are plotted with strain rate in the proceeding section. The variation of $\ln \left(\sigma_{\mathrm{e}}\right)$ as a function of $\ln (\hat{\varepsilon})$ is shown in Fig 5(a). It is noted that the elastic limit stress decreases gradually with strain rate in case of $0.5 \mathrm{wt} \% \mathrm{Mg}$ concentration. But at $1 \mathrm{wt} \% \mathrm{Mg}$, the elastic limit stress remained almost invariant to the strain rate. On the other hand, at $1.5 \mathrm{wt} \% \mathrm{Mg}$, the elastic limit increases gradually with increase in strain rate. The proof stress and plastic strengthening coefficient also follow the similar trend to that observed in the case of elastic limit stress. It is further noted that, elastic limit stress is almost comparable to that of elastic limit stress (within $10-20 \%$ variation in very few cases) and these are proportional to each other. The slope of best linear fit of $\ln \left(\sigma_{\mathrm{e}}\right) \mathrm{vs}$. $\ln (\dot{\varepsilon})$ gives the value of ' $\mathrm{m}$ ' the strain rate sensitivity, and the antilog of intersection of the best fit line gives the value of strain rate strengthening coefficient, ' $\mathrm{K}_{\mathrm{s}}$ '. Similarly, $\ln \left(\sigma_{\mathrm{y}}\right)$ vs. $\ln (\dot{\varepsilon})$ is also plotted and the value of ' $\mathrm{m}$ ' and ' $\mathrm{K}_{\mathrm{s}}$ ' for ' $\sigma_{\mathrm{y}}$ ' - strain rate relation are measured. The value of ' $\mathrm{m}$ ' and ' $\mathrm{K}_{\mathrm{s}}$ ' as a function of $\mathrm{Mg}$ concentration for the case of ' $\sigma_{\mathrm{e}}$ ' and ' $\sigma_{\mathrm{y}}$ ' are reported in Table 2 .

Table 2 strain rate sensitivity and strain rate strengthening coefficient of the alloy in case of elastic limit stress and $0.2 \%$ proof stress

\begin{tabular}{|c|c|c|c|c|}
\hline \multirow{2}{*}{ Material (in wt\%) } & \multicolumn{2}{|c|}{ Elastic limit $\left(\boldsymbol{\sigma}_{\mathbf{e}}\right)$ criteria } & \multicolumn{2}{c|}{ Proof stress $(\mathbf{0 . 2 \%}) \mathbf{( \sigma _ { \mathbf { y } } ) \text { criteria }}$} \\
\cline { 2 - 5 } & $\mathbf{m}$ & $\mathbf{K}_{\mathbf{s}}(\mathbf{M P a})$ & $\mathbf{m}$ & $\mathbf{K}_{\mathbf{s}}(\mathbf{M P a})$ \\
\hline $0.50 \%$ & -0.05 & 34.50140335 & -0.028 & 47.60796123 \\
\hline $1 \%$ & -0.012 & 64.45710733 & 0.005 & 66.55309166 \\
\hline $1.50 \%$ & 0.063 & 90.7401566 & 0.062 & 90.0171313 \\
\hline
\end{tabular}

The variation of plastic strength coefficient. $\mathrm{K}$, as a function of $\ln$ (strain rate) is shown in Fig 5(c). It is noted that $\mathrm{K}$ decreases with strain rate in case of $0.5 \mathrm{wt} \%$, remained almost invariant with strain rate, in case of $1.0 \mathrm{wt} \% \mathrm{Mg}$, and increases with strain rate in case of $1 \mathrm{wt} \% \mathrm{Mg}$. However, the variation of ' $\mathrm{K}$ ' with strain rate (either increase or decrease) is very marginal. The variation of ' $n$ ' as a function of $\ln$ (strain rate) is shown in Fig. 5(d). It is noted that the strain hardening coefficient ' $n$ ' is remained almost invariant to the strain rate, irrespective of $\mathrm{Mg}$ concentration. However, it is noted that ' $\mathrm{n}$ ' increases marginally with strain rate, in case of $1.5 \mathrm{wt} \% \mathrm{Mg}$. This is primarily attributed to greater plastic constraint due to presence of higher Mg concentration. Very low value of $\mathrm{m}$ indicates that materials are almost strain rate insensitive. But marginally greater and positive value of $\mathrm{m}$ in case of $1.5 \mathrm{at} \% \mathrm{Mg}$ alloy indicates that this alloy is relatively strain rate sensitive.

\section{Effect of Mg Concentration:}

The trend of variation of the deformation response with strain rate is earlier noted to be influenced with the $\mathrm{Mg}$ concentration. This is due to the variation of microstructure with $\mathrm{Mg}$ concentration. In order to understand the variation of these deformation responses with $\mathrm{Mg}$ concentration, the deformation responses were plotted as a function of $\mathrm{Mg}$ concentration. Fig 6(a) depicts that ' $\sigma_{\mathrm{e}}$ ' increases monotonically with increase in $\mathrm{Mg}$ concentration. Similar tends of variation of ' $\sigma_{\mathrm{y}}$ ' with $\mathrm{Mg}$ concentration is noted in Fig 6(b). In both the figures, it is noted that at $0.01 / \mathrm{s}$ strain rate, there is no further increase in stress when $\mathrm{Mg}$ concentration increases from $1 \mathrm{wt} \%$ to $1.5 \mathrm{wt} \%$. However on an average, ' $\sigma_{\mathrm{y}}$ ' and ' $\sigma_{\mathrm{e}}$ ' increase with increase in $\mathrm{Mg}$ concentration. The plastic strengthening coefficient ' $\mathrm{K}$ ' also increases with increase in $\mathrm{Mg} \%$ (Fig 6(c)). This is attributed to refinement of microstructure, increase in $\mathrm{MgCa}_{2}$ intermetallic phases in the alloy and greater solid solution strengthening. The strain hardening exponent dictate the rate at which the materials get harden during progressive plastic deformation. It is related to strengthening of matrix due to dislocation-dislocation interaction, interaction of slip plane which primarily govern by matrix crystal structure and orientation dislocation . It is expected, that in as-cast conditions, these factors are invariant to $\mathrm{Mg} \%$ which finally resulting in almost no variation of ' $\mathrm{n}$ ' with $\mathrm{Mg} \%$. However, the dislocation interaction and accommodation of dislocation depends on strain rate and this results in marginally higher ' $n$ ' at higher strain rate especially when $\mathrm{Mg}$ content is $1.5 \mathrm{wt} \%$.

\section{Effect of strain rate and $\mathrm{Mg}$ concentration on flow stress:}

The flow stress $\left(\sigma_{\mathrm{f}}\right)$ at different strain $(\varepsilon)$ as a function of strain rate $(\dot{\varepsilon})$ are plotted to determine strain rate strengthening coefficient for flow stress ' $\mathrm{K}_{\mathrm{sf}}$ ' and strain rate sensitivity of flow stress ' $\mathrm{m}_{\mathrm{sf}}$ ' at different strain for varying Mg concentration in Fig.7. It is evident from Figs 7 (a), (b) and (c) that $\sigma_{\mathrm{f}}$ increases with strain rate marginally irrespective of strain and $\mathrm{Mg}$ concentration. The increase of $\sigma_{\mathrm{f}}$ with strain indicats strain hardening of the materials. The ' $\mathrm{m}_{\mathrm{sf}}$ ' and ' $\mathrm{K}_{\mathrm{sf}}$ ' for $\sigma_{\mathrm{f}}$ - strain rate relationships are determined from the best linear fit of the curves shown in Fig.7. The values of ' $\mathrm{m}_{\mathrm{sf}}$ ' and ' $\mathrm{K}_{\mathrm{sf}}$ ' as a function of strain and $\mathrm{Mg}$ concentration are reported in Table 3.

It is evident from Table 3 
Table 3: The strain rate sensitivity and the strength coefficient at different strain.

\begin{tabular}{|c|c|c|c|}
\hline Mg in Wt \% & Strain & Strain rate sensitivity ' $\mathrm{m}_{\mathrm{sf}}$ ' & Strength Coefficient ' $K_{\mathrm{sf}}$ ' \\
\hline \multirow{5}{*}{$0.5 \mathrm{wt} \%(20 \mathrm{gm})$} & 0.05 & 0.108 & 48.47266351 \\
\hline & 0.1 & 0.106 & 56.09238143 \\
\hline & 0.15 & 0.103 & 71.02273237 \\
\hline & 0.2 & 0.094 & 82.18723516 \\
\hline & 0.25 & 0.091 & 91.65211033 \\
\hline \multirow{5}{*}{$1.0 \mathrm{wt} \%$ (40 gm) } & 0.05 & 0.15 & 78.96462758 \\
\hline & 0.1 & 0.145 & 99.98298285 \\
\hline & 0.15 & 0.15 & 111.6088112 \\
\hline & 0.2 & 0.121 & 116.6292383 \\
\hline & 0.25 & 0.105 & 120.7835378 \\
\hline \multirow{5}{*}{$1.5 \mathrm{wt} \%(60 \mathrm{gm})$} & 0.05 & 0.119 & 90.46834405 \\
\hline & 0.1 & 0.126 & 116.9796514 \\
\hline & 0.15 & 0.095 & 127.7403898 \\
\hline & 0.2 & 0.086 & 135.6394144 \\
\hline & 0.25 & 0.08 & 141.4575964 \\
\hline
\end{tabular}

that both ' $\mathrm{m}_{\mathrm{sf}}$ ' and $\mathrm{K}_{\mathrm{sf}}$ are varying strain and $\mathrm{Mg}$ concentration. ' $\mathrm{K}_{\mathrm{sf}}$ ' is increasing monotonically with strain, But ' $\mathrm{m}_{\mathrm{sf}}$ ' remains constant upto strain of 0.1 to 0.15 , and then decreases with further increase in strain (Fig.9(a)). Relatively lower value of ' $\mathrm{m}_{\mathrm{sf}}$ ' at higher strain indicates that flow stress at higher strain is relatively less sensitive to strain rate. This is attributed to the fact that at higher strain value relatively larger extent of damage likes micro voids, microcracks etc generated which annihilates dislocation interaction and multiplication. But, the value of ' $\mathrm{K}_{\mathrm{sf}}$ ' increases significantly and monotonically with strain irrespective of magnesium concentration (Fig.9(b)). This is attributed to greater constraint of plastic deformation of the alloy due to generation of more microvoids, voids - dislocation interacton, interaction amongst slip bands etc. The combined effect of strain on ' $\mathrm{K}_{\mathrm{sf}}$ ' and ' $\mathrm{m}_{\mathrm{sf}}$ ' makes the over all variation of flow stress with strain. As a result, $\sigma_{\mathrm{f}}$ increases with increase in strain even though flow stress decreases marginally with strain rate. It is further noted that ' $\mathrm{K}_{\mathrm{sf}}$ ' increases with strain following a linear relation. The strain rate sensitivity ' $\mathrm{m}_{\mathrm{sf}}$ ' is noted to be the maximum at $1 \mathrm{wt} \% \mathrm{Mg}$ (Fig. 9(a)). But, the overall variation is low especially at higher strain. This is because of the fact that room at room temperature deformation of Al-alloys and composites are relatively in sensitive to strain rate [13]. The ' $\mathrm{K}_{\mathrm{sf}}$ ' on the other hand increases with increase in Mg concentration (Fig. 9 (b)) relatively at larger extent.

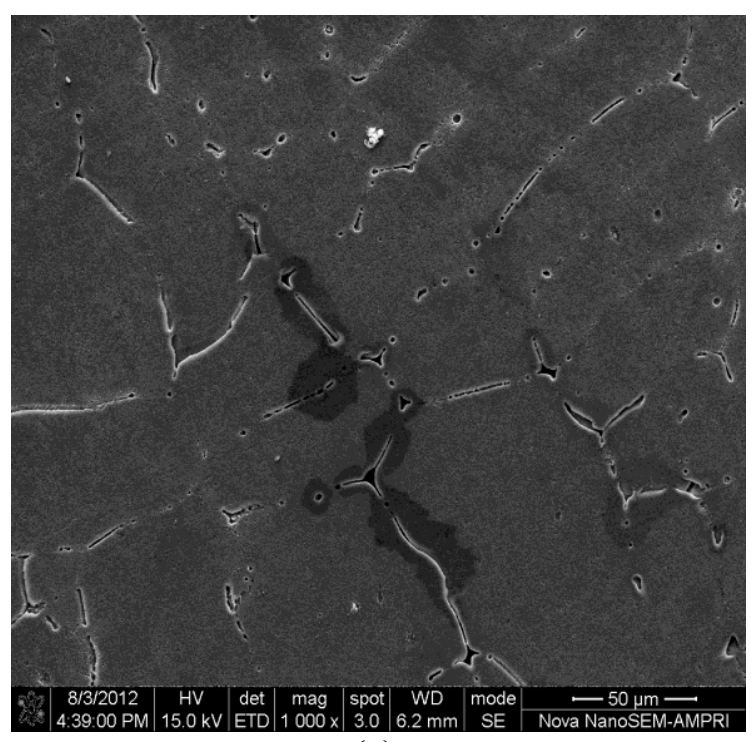

(a)

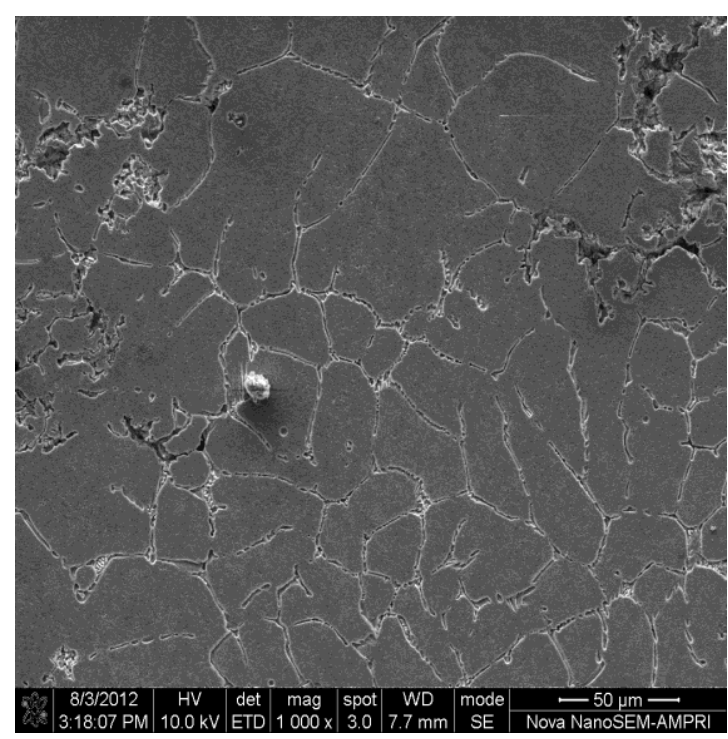

(b) 


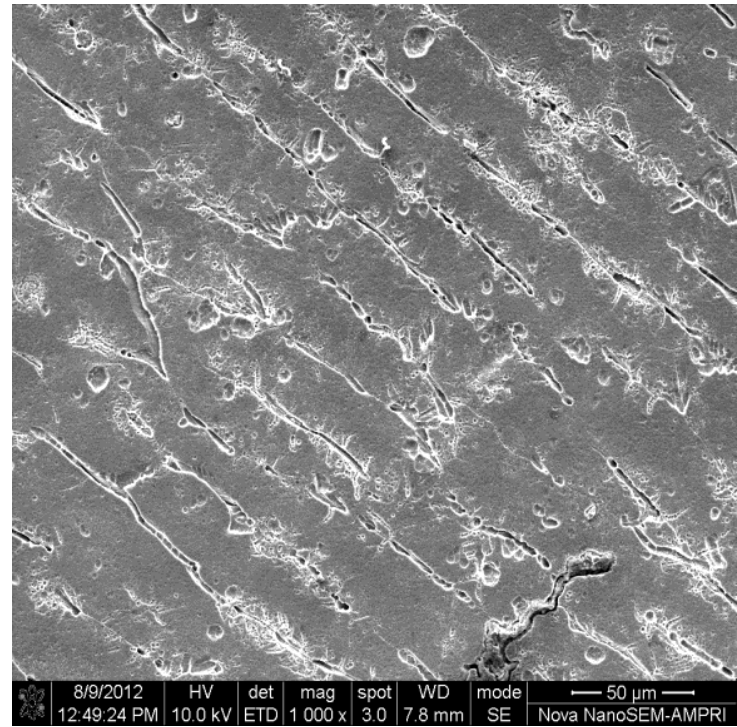

(c)

Fig.1: Microstructure of Al-Ca-Mg Alloy With (a) $0.5 w 1 \% \mathrm{Mg}$ (b) $1 \mathrm{wt} \% \mathrm{Mg}$ (c) $1.5 w \mathrm{wt} \% \mathrm{Mg}$.

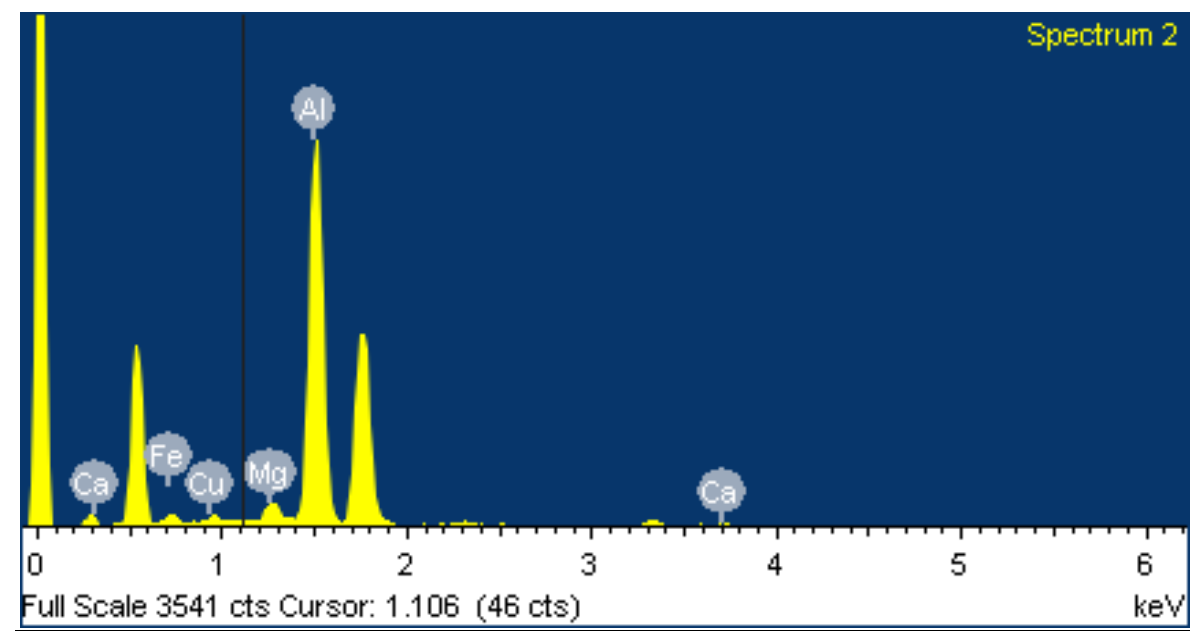

Fig. 2 EDX of Al-Ca-Mg Alloy

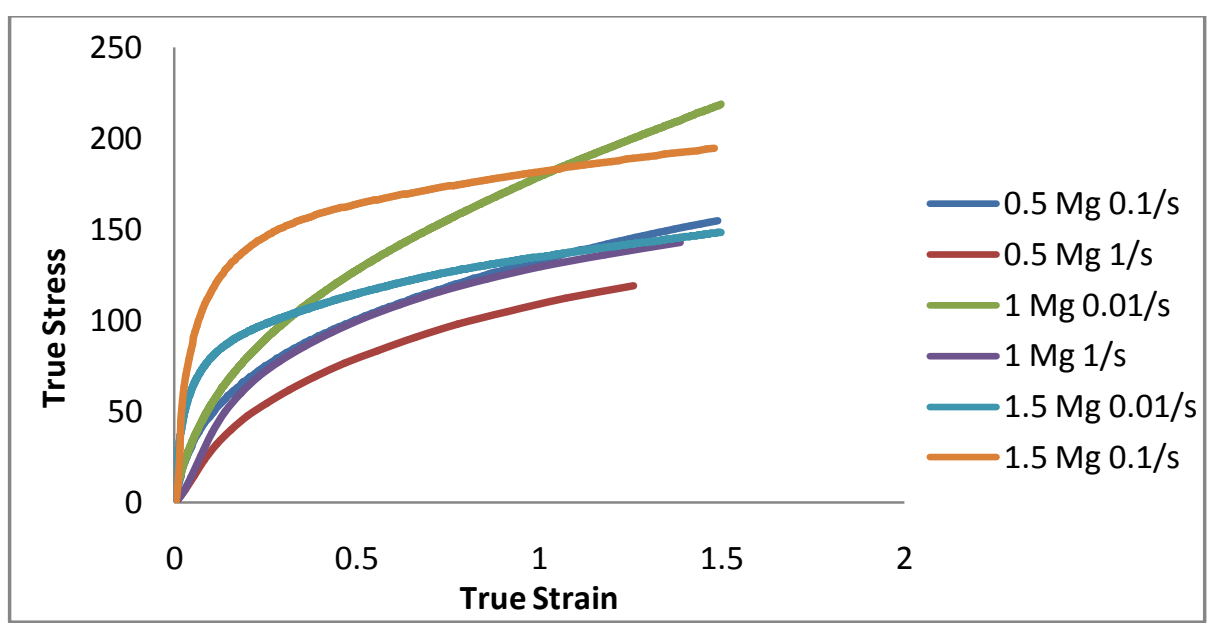

Fig.3: Variation of true stress vs. true strain at different strain rate for Al-Ca-Mg alloy 


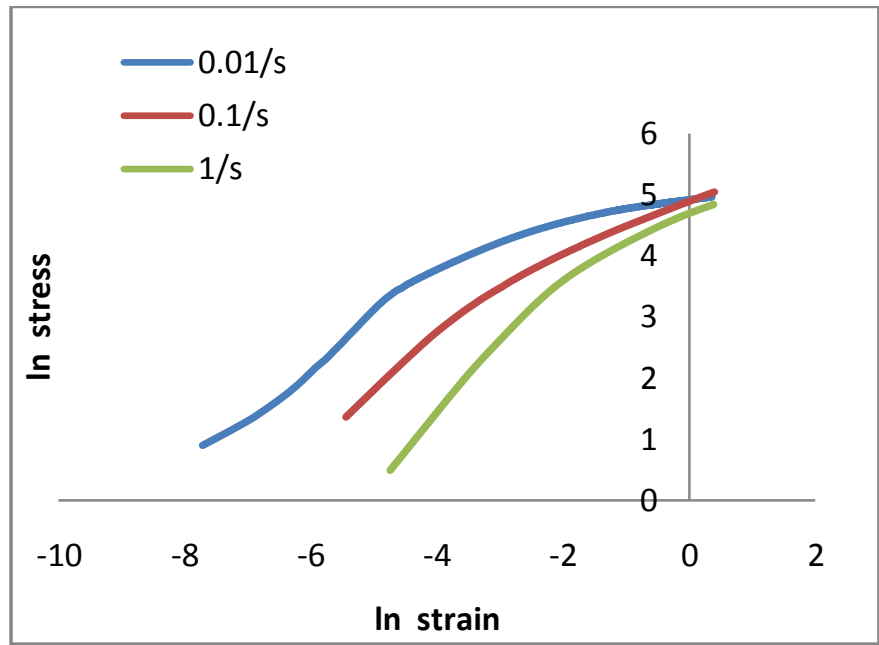

(a)

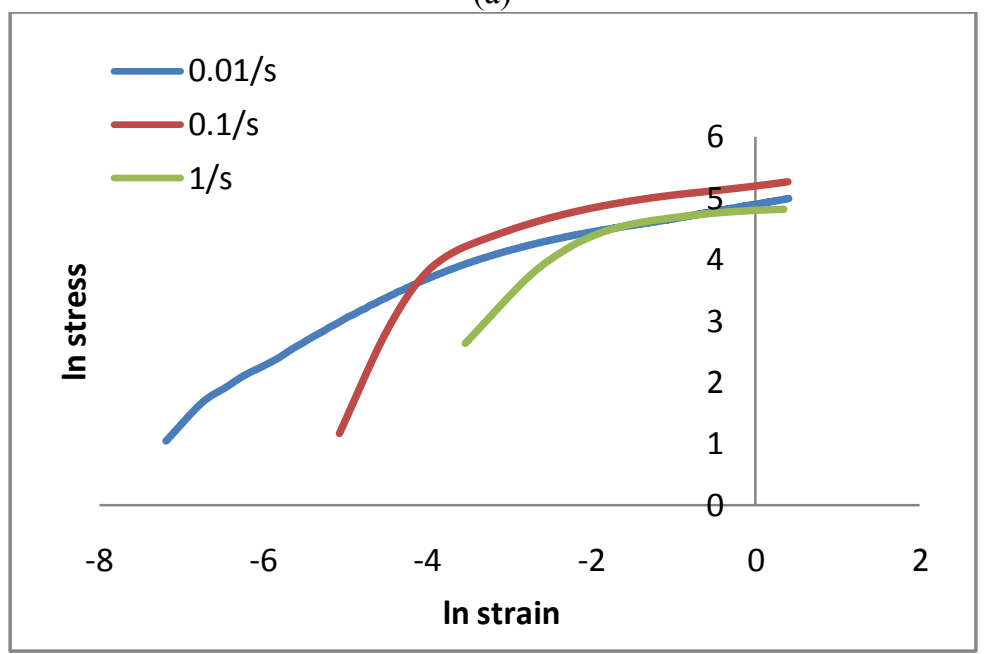

(b)

Fig.4: Variation of In (stress) vs. In (strain) at different strain rate for Al-Ca-Mg alloy with (a) $0.5 w t \% \mathrm{Mg}$ (b) $1.5 \mathrm{wt} \% \mathrm{Mg}$.

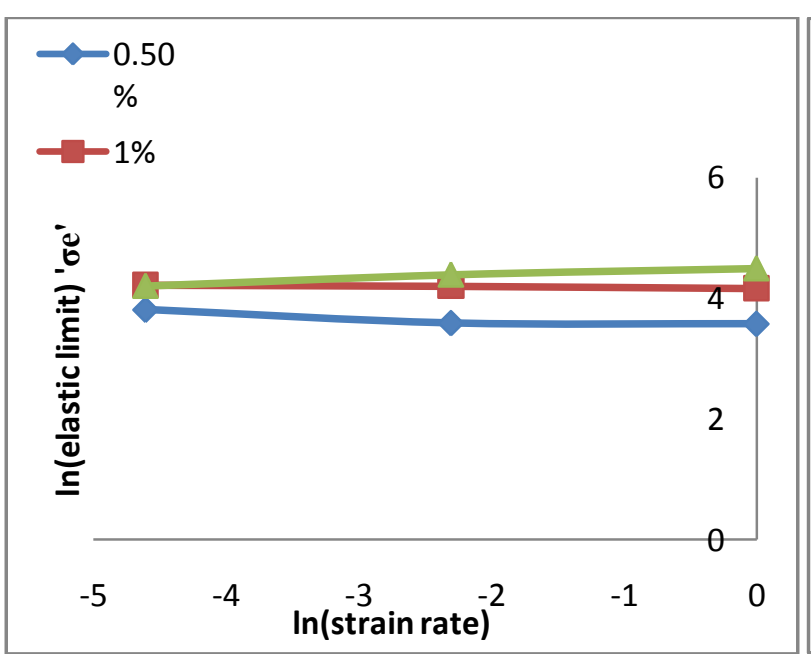

(a)

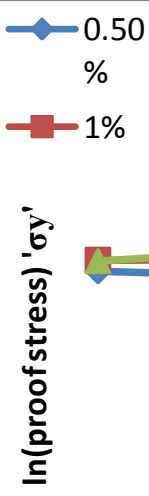
In(strain rate)

(b) 


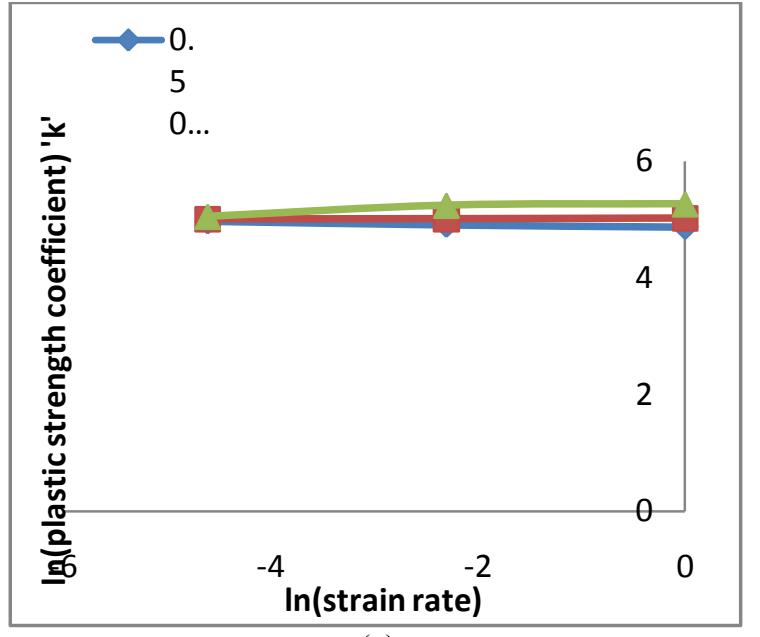

(c)

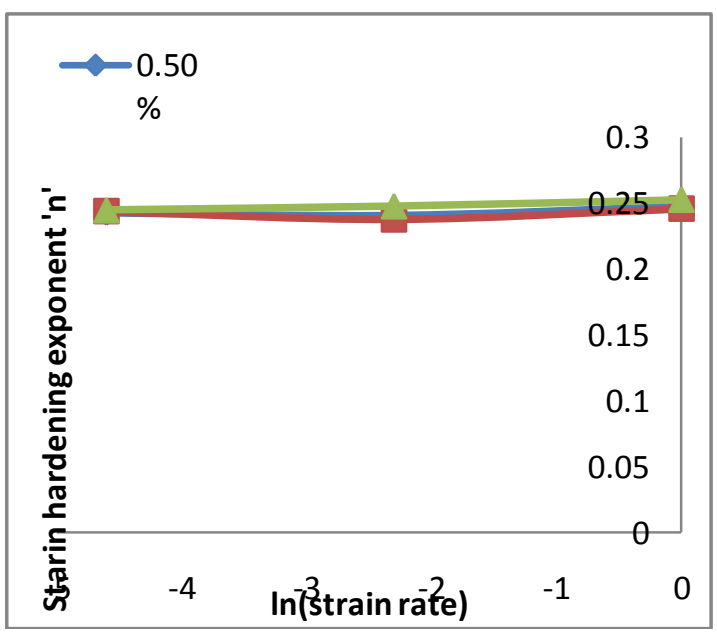

(d)

Fig.5. Variation of (a) elastic limit, (b) proof stress, (c) strain hardening exponent and (d) plastic strength coefficient, with In (strain rate)

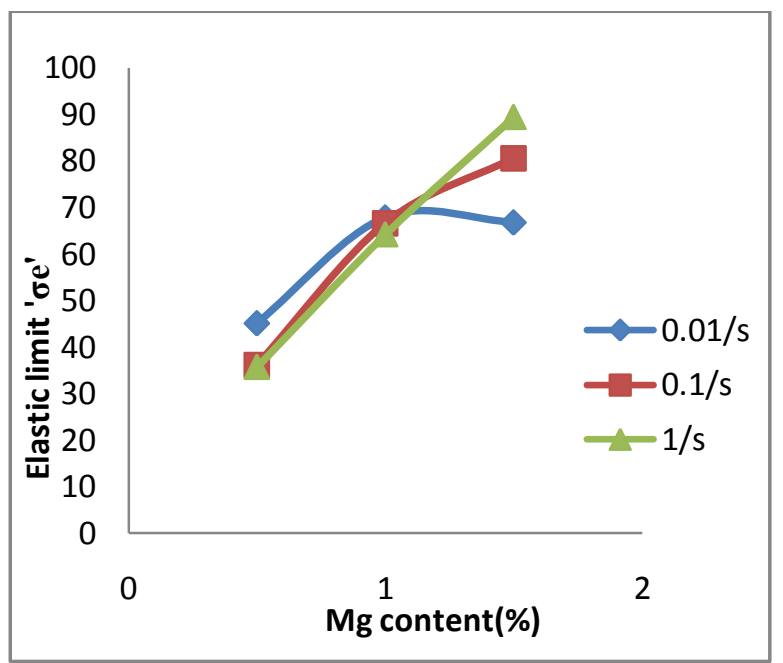

(a)

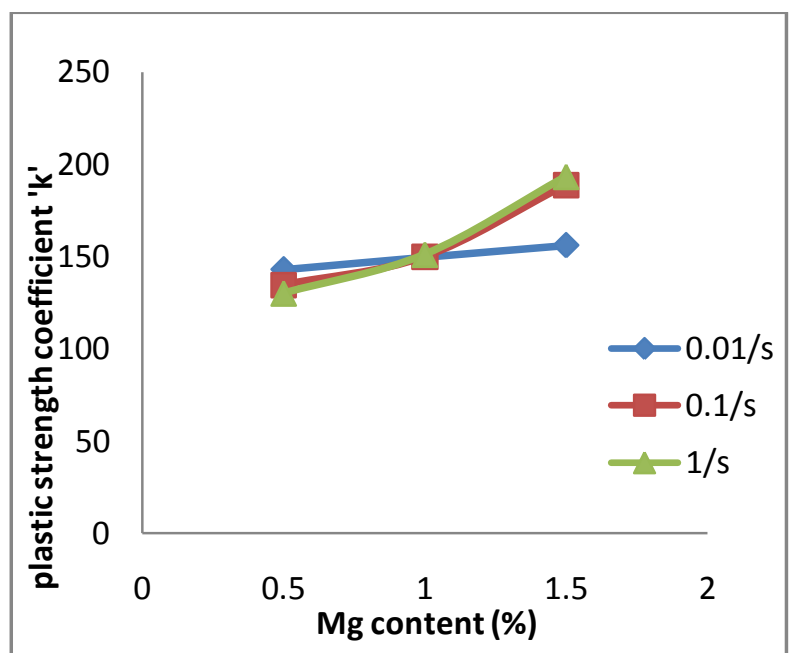

(c)

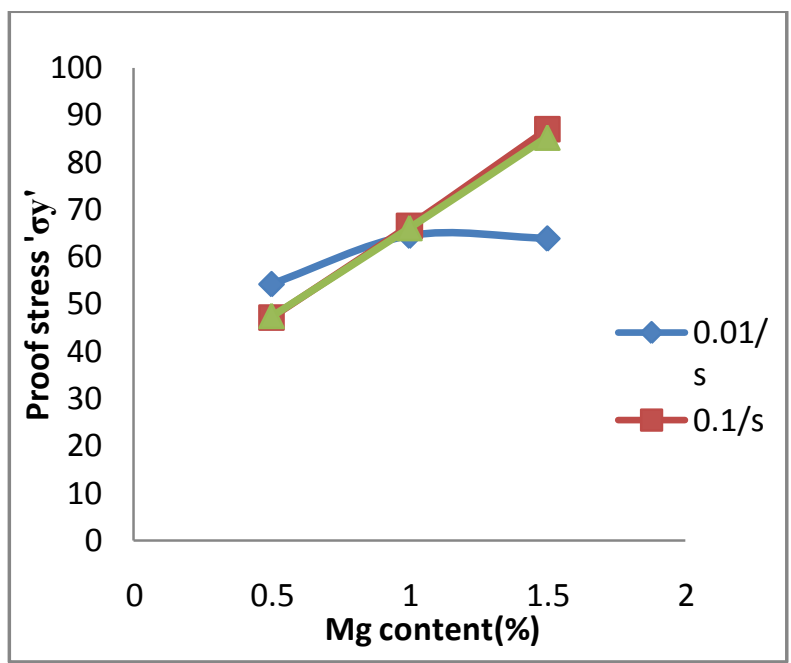

(b)

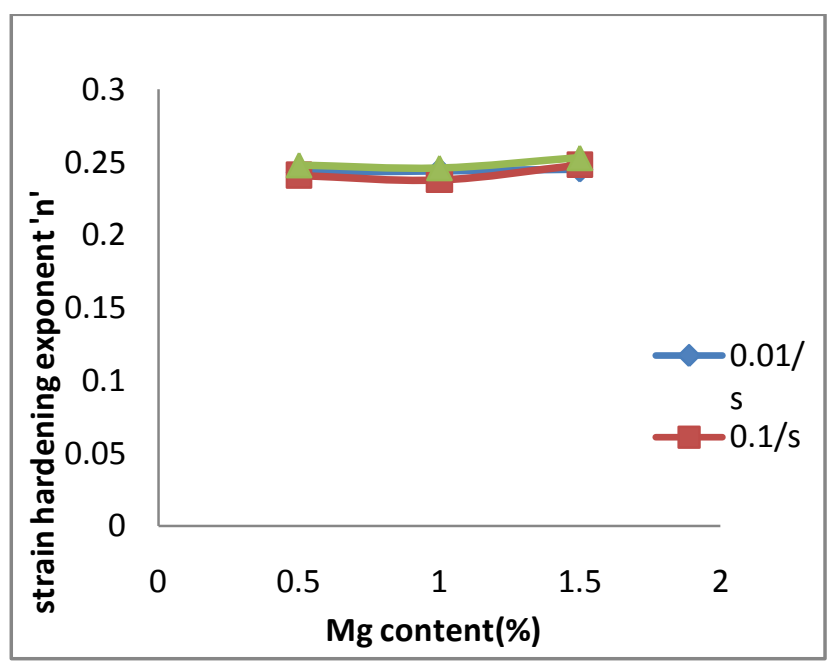

(d)

Fig.6. Variation of (a) elastic limit, (b) proof stress, (c) strain hardening exponent and (d) plastic strength coefficient, with Mg concentration 


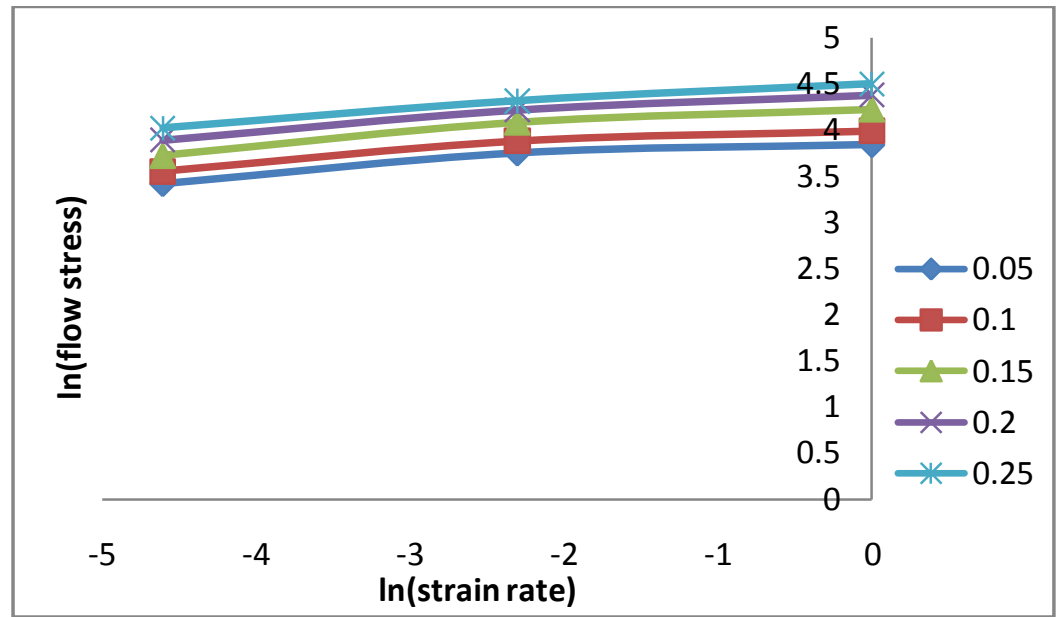

(a)

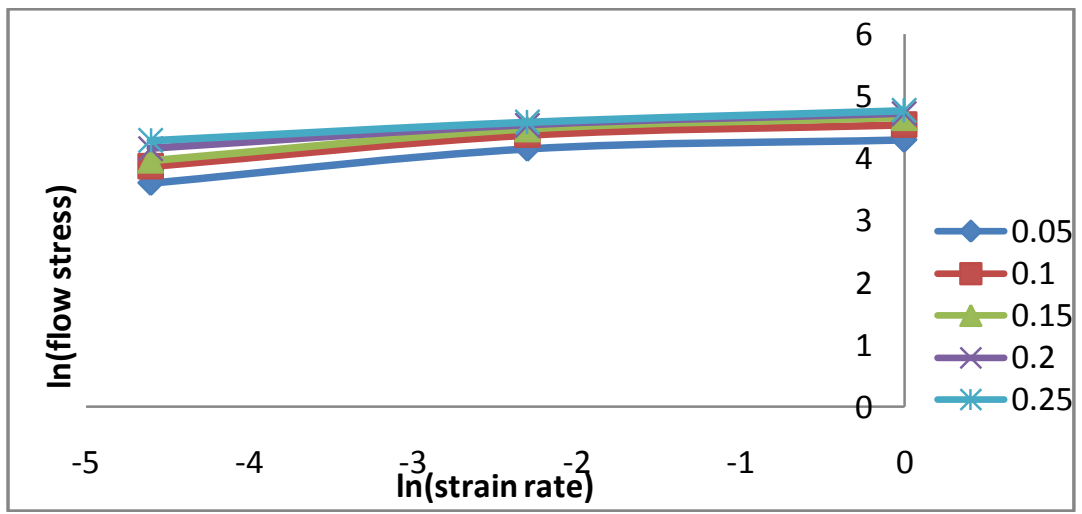

(b)

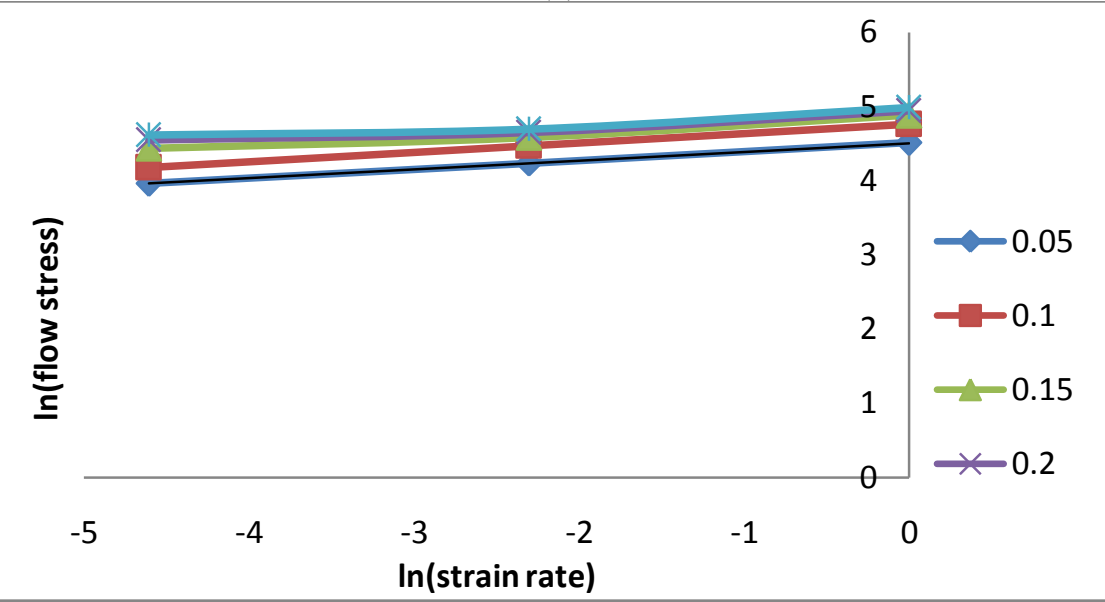

(c)

Fig: 7. Variation of In (flow stress) vs. In (strain rate) at fixed strain for Al-Ca-Mg alloy with (a) $0.5 \mathrm{wt} \% \mathrm{Mg}$, (b) $1 \mathrm{wt} \% \mathrm{Mg}$ and, (c) $1.5 \mathrm{wt} \% \mathrm{Mg}$. 


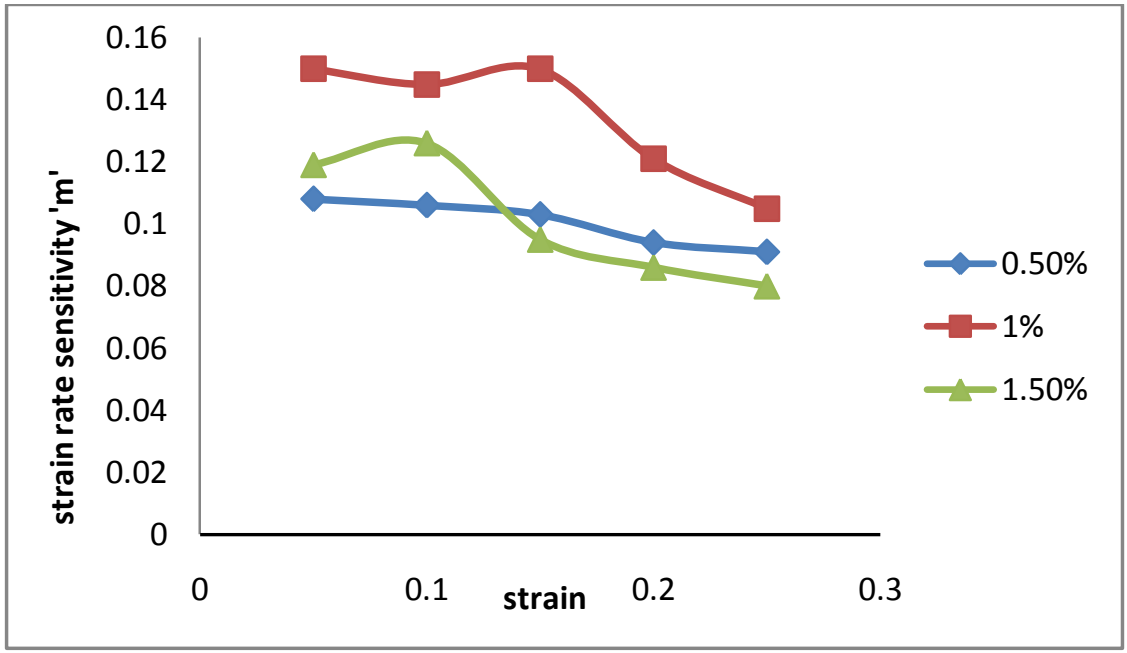

(a)

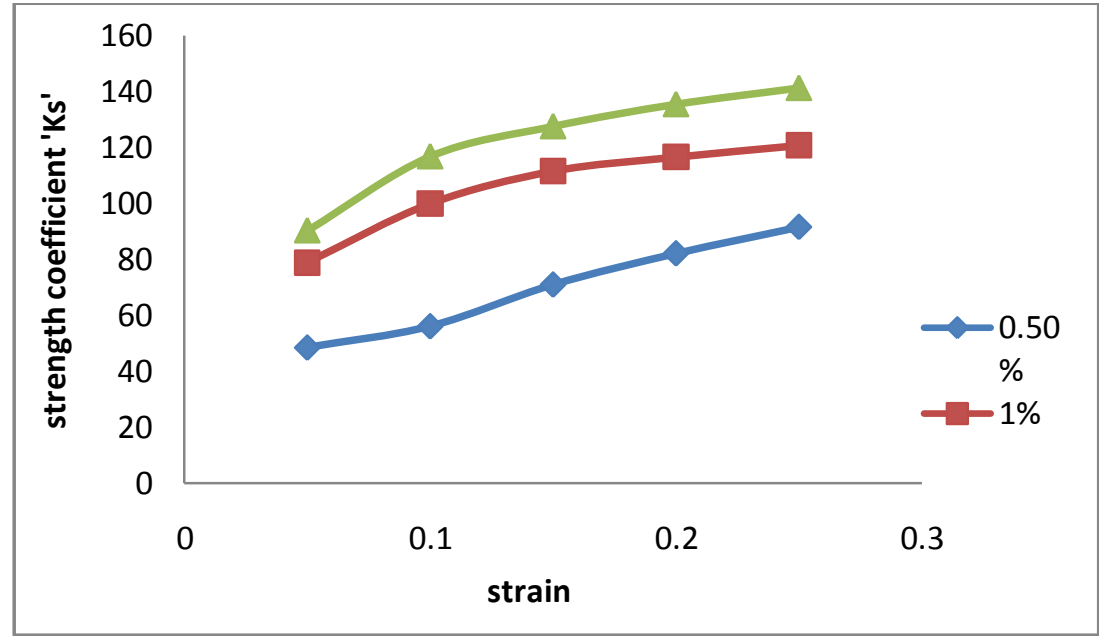

(b)

Fig.8: Variation of (a) strain rate sensitivity, (b) strength coefficient with strain

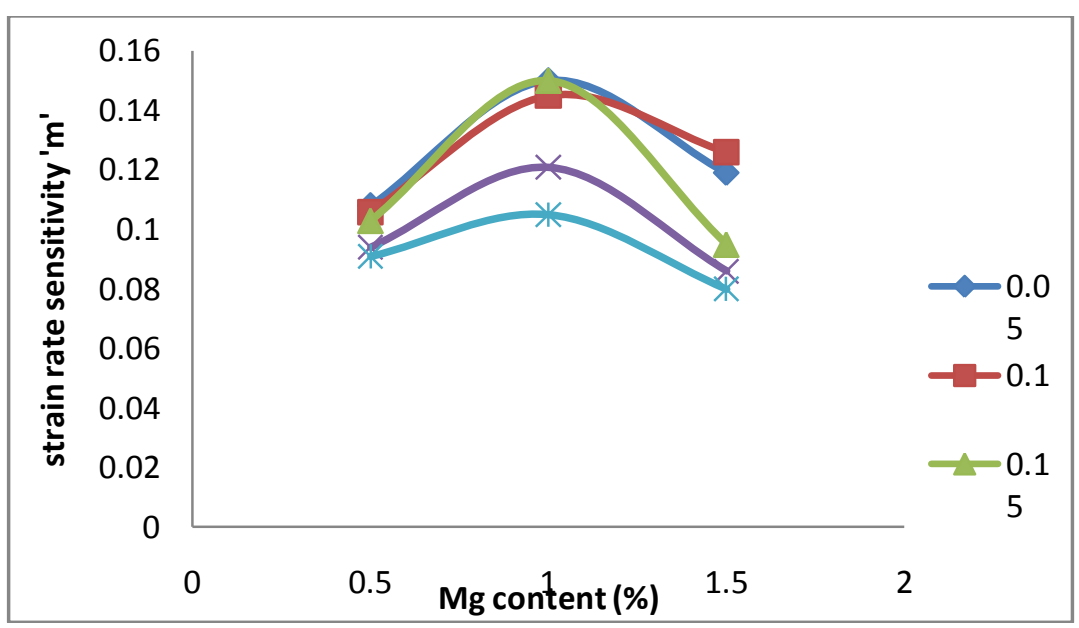

(a) 


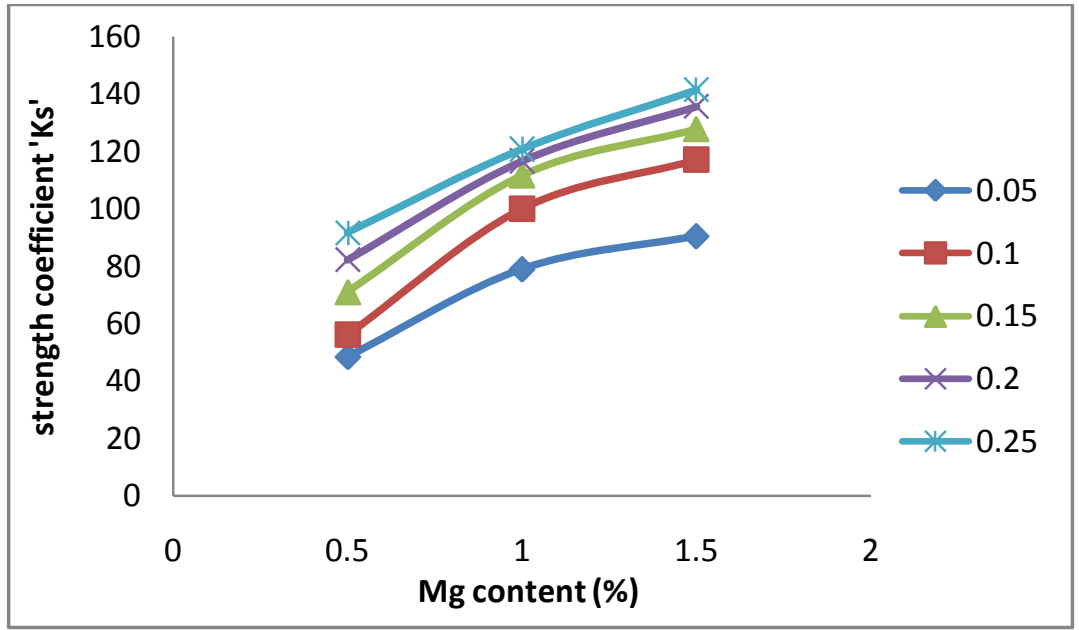

(b)

Fig.9: Variation of (a) strain rate sensitivity, (b) strength coefficient with Mg concentration

The following are the conclusions:

\section{Conclusions}

1) The deformation response of $\mathrm{Al}-\mathrm{Ca}-\mathrm{Mg}$ alloy varies with the variation of $\mathrm{Mg}$ concentration and strain rate. In case of $0.5 \mathrm{wt} \% \mathrm{Mg}$, the elastic limit stress, $0.2 \%$ proof stress, plastic strengthening coefficient decreases with strain rate. But, incase of $1.0 \mathrm{wt} \% \mathrm{Mg}$ concentration, these parameters are almost invariant to the strain rate. When the $\mathrm{Mg}$ concentration increases to $1.5 \mathrm{wt} \%$, these parameters increases monotonically with strain rate indicating greater degree of strain rate sensitivity.

2) The strength hardening exponent, on the other hand, remains almost invariant to the strain rate and $\mathrm{Mg}$ concentration. However, alloy containing $1.5 \mathrm{wt} \% \mathrm{Mg}$ showed marginally higher value of strain hardening exponent.

3) The flow curves of Al-Ca-Mg alloy having $0.5 \%, 1 \%$ and $1.5 \%$, of $\mathrm{Mg}$ exhibits similar trend irrespective of strain rate. The flow stress increases with strain. The strain rate sensitivity, in case of yield stress and elastic limit stress, remained negative wheat $\mathrm{Mg}$ concentration of $0.5 \mathrm{wt} \%$, almost zero in case of $1.0 \mathrm{wt} \% \mathrm{Mg}$ and Positive incase of $1.5 \mathrm{wt} \% \mathrm{Mg}$. Plastic strengthening coefficient increases with increase in $\mathrm{Mg}$ concentration irrespective of $\mathrm{Mg}$ concentration.

4) The strain rate sensitivity, in case of flow stress, remains almost invariant to strain up to a strain value of 0.15. Beyond that it decreases with strain. But the strain rat4e strengthening coefficient, in case of flow stress, increases with increase in strength. Combined effect of these parameters with strain, led to increase of flow stress with strain.

5) The strain rate strengthening coefficient of the alloy increases with increase in Mg concentration irrespective of the strain rate. However, the strain rate sensitivity of the flow stress is observed to be maximum when the alloy contains $1.0 \mathrm{wt} \% \mathrm{Mg}$.

6) The variation of deformation response of this alloy with strain, strain rate and $\mathrm{Mg}$ concentration is due to variation in microstructure, micro-deformation mechanism, variation of voids and dislocation structure.

\section{References:}

[1]. Davis J. R. (1999). Corrosion of Aluminum and Aluminum Alloys (\#06787G), ASM International, Philadelphia, USA, p 1-4.

[2]. D.P.Mondal, Nidhi Jha, Anshul Badkul, S.Das, M.S.Yadav, Prabhash Jain."Effect of calcium addition on the microstructure and compressive deformation behavior 7178 aluminum alloy" Material and Design 32(2011) 2803-2812.

[3]. R.C. Picu, G. Vincze, F. Ozturk, J.J. Gracio, F. Barlat, A.M. Maniatty, "Strain rate sensitivity of the commercial aluminum alloy AA5182-O" Materials Science and Engineering A 390 (2005) 334-343.

[4]. Miller WS, Heinz A, Haszler A, Keidel C, Moldenhauer S, Benedictus R. Recent development in aluminium alloys for aerospace applications. Mater Sci Eng A 2000;280:102-7.

[5]. Strake EA, Staley JT. Applications of modern aluminium alloys to aircraft. Progress Aerospace Sci 1999; 32:131-72.

[6]. Froes FH. Advanced metals for aerospace and automotive use. Mater Sci Eng A 1994; 184:119-33.

[7]. L.L.Rokhlin and N.I.Nikitina. "Effect of calcium on the properties of the Mg-Al system. Nonferrous Metals and Alloys, vol. 45, May 2003

[8]. Kai ZHU Jian YANG, Rui-zhi WANG, Zhen-guo YANG. "Effect of Mg Addition on Inhibiting Austenite Grain Growth in Heat Affected Zones of Ti-Bearing Low Carbon Steels". Journal Iron and Steel Research, International 2011;18: 60-64.

[9]. Shoichi Hirosawa, Tatsuo Sato, Akihiko Kamio. "Effects of Mg addition on the kinetics of low-temperature precipitation in Al-Li$\mathrm{Cu}-\mathrm{Ag}-\mathrm{Zr}$ alloys". Materials Science and Engineering: A 1998; 242:195-201.

[10]. S. Valdez, J. Genescá B. Campillo, O. Flores R. Pérez, J.A. Juárez-Islas. "Effect of Mg addition on the $\tau$ phase distribution of an AlMn alloys modified with zinc". Materials Letters 2008; 62: 1139-1142. 
[11]. J. Gubicza, N.Q. Chinh, Z. Horita, T.G. Langdon. "Effect of Mg addition on microstructure and mechanical properties of aluminum". Materials Science and Engineering: A 2004; 387-389: 55-59.

[12]. Aidang Shan, Wei Fang, Hitoshi Hashimoto, Yong-Ho Park. "Effect of Mg addition on the microstructure and mechanical properties of $\mathrm{MoSi}_{2}$ alloys." Scripta Materialia 2002; 46: 645-648.

[13]. Mondal DP, Ganesh NV, Muneshwar VS, Das S, Ramakrishnan N. Effect of SiC concentration and strain rate on the compressive deformation behaviour of 2014Al-SiCp composite. Mater Sci Eng A 2006; 433:18-31. 